\title{
Effects of initial a-phase content on the electrical, thermal, and mechanical properties of pressureless solid-state sintered SiC ceramics
}

Rohit MALIK

University of Seoul

Young-Wook Kim ( $\square$ ywkim@uos.ac.kr)

University of Seoul https://orcid.org/0000-0001-6275-0323

\section{Research Article}

Keywords: SiC, microstructure, electrical properties, thermal conductivity, mechanical properties

Posted Date: August 3rd, 2021

DOI: https://doi.org/10.21203/rs.3.rs-744888/v1

License: (c) (i) This work is licensed under a Creative Commons Attribution 4.0 International License.

Read Full License 


\section{Abstract}

aand $\beta$-SiC starting powders of similar particle sizes were used to investigate the effect of initial a-phase content on the electrical, thermal, and mechanical properties of pressureless solid-state sintered (PSS) $\mathrm{SiC}$ ceramics with $\mathrm{B}_{4} \mathrm{C}$ and $\mathrm{C}$. For $\beta$-SiC starting powders, a coarse-grained microstructure with elongated platelet grains formed by the $3 \mathrm{C}$ to $6 \mathrm{H}$ to $4 \mathrm{H}-\mathrm{SiC}$ phase transformation was obtained. In contrast, $\mathrm{a}-\mathrm{SiC}$ powders exhibited a fine-grained microstructure with platelet grains. The electrical resistivity decreased by an order of magnitude with increasing initial a-phase content presumably due to (1) an increased $6 \mathrm{H}-\mathrm{SiC}$ content causing a decrease in bandgap energy and (2) the low soluble impurity content ( $\mathrm{Fe}$ and $\mathrm{V}$ ) of the a-SiC powders. The thermal conductivity increased by approximately $32 \%$ with increasing initial a-phase content due to (1) an increased $6 \mathrm{H}-\mathrm{SiC}$ content, which has a higher intrinsic thermal conductivity compared to $4 \mathrm{H}$ and (2) the low impurity content of the a-SiC powders. The flexural strength increased by approximately $16 \%$ with increasing initial a-phase content due to a decreased flaw size with decreasing grain size. However, the fracture toughness and hardness were insensitive to the change in initial a-phase content.

\section{Introduction}

Pressureless solid-state sintered (PSS) silicon carbide (SiC) ceramics exhibit superior hardness, oxidation resistance, corrosion resistance, and wear resistance compared to those of liquid phase sintered (LPS) SiC ceramics [1-22]. However, there has been limited research on PSS SiC ceramics presumably due to their moderate mechanical properties and high processing temperatures compared to those of LPS SiC ceramics. Recently, there is renewed interest in PSS SiC ceramics due to their desirable engineering properties, which are well suited for various industrial applications such as wafer boats, susceptors, focus rings, and dummy wafers in the semiconductor processing industry; and mechanical seals and bearings in fluid machinery.

Prochazka [2] first developed PSS SiC ceramics using B and C as sintering aids. It was postulated that B segregates at the grain boundaries and reduces the grain boundary energy $\left(\mathrm{V}_{\mathrm{GB}}\right)$ and $\mathrm{C}$ increases the surface energy $\left(\mathrm{Y}_{\mathrm{SV}}\right)$ of $\mathrm{SiC}$ by removing the native $\mathrm{SiO}_{2}$ film via a carbothermal reduction process. The combined effect of both additives reduces $\mathrm{Y}_{\mathrm{GB}} / \mathrm{Y}_{\mathrm{SV}}$ to a subcritical value, thus making the densification process thermodynamically feasible [23]. Unlike LPS ceramics [24-39], where mechanical, thermal, and electrical properties can be tuned using a wide range of additive compositions, the scope of PSS SiC ceramics is constrained by the limited choice of sintering additives. The additive systems are limited to elemental $\mathrm{B}$ and $\mathrm{B}$-compounds such as $\mathrm{B}_{4} \mathrm{C}$ powders, $\mathrm{BCl}_{3}$ gas, and $\mathrm{LiBH}_{4}$ and $\mathrm{H}_{3} \mathrm{BO}_{3}$ solutions [1].

To harness the full potential of PSS SiC ceramics, it is important to explore new additives and processing strategies. Recently, BN has been reported as a new sintering additive for PSS SiC ceramics [40]. One potential strategy is to use different crystalline phases $(\alpha / \beta)$ of the starting $\mathrm{SiC}$ powders. Previous works $[24,25]$ on LPS SiC ceramics had established that microstructure and mechanical properties could be tailored by varying the initial $\alpha$ - and $\beta$-phase content. It was demonstrated that increasing initial $\beta$-phase 
content was beneficial in improving the fracture toughness attributed to the crack deflection by a-SiC platelet grains formed in situ via $\beta$ to a phase transformation during sintering $[24,25]$ whereas a finegrained microstructure with equiaxed grains resulted in improved flexural strength with increasing initial a-phase content [24]. For PSS SiC ceramics, a previous work [7] revealed interesting microstructural characteristics for $\mathrm{a}-\mathrm{SiC}$ and $\beta-\mathrm{SiC}$ powders sintered with $0.4 \mathrm{wt} \% \mathrm{~B}_{4} \mathrm{C}$ and $2 \mathrm{wt} \% \mathrm{C}$ at $2150^{\circ} \mathrm{C}$ in flowing Ar gas. For a-SiC powders, a fine-grained microstructure was obtained. On the other hand, $\beta$-SiC starting powders exhibited a coarse-grained microstructure with elongated platelet grains of high aspect ratio formed via $\beta$ to a phase transformation of SiC during sintering. However, there was little systematic research to be found on the effects of initial a-SiC content on the electrical, thermal, and mechanical properties of PSS SiC ceramics.

This study is a novel investigation on the effect of initial a-SiC content (0-100\%) on the electrical, thermal, and mechanical properties of PSS SiC ceramics. Given that the initial a- and $\beta$-phase content have a profound effect on the microstructure [7], it would be interesting to investigate the effect of such tailored microstructures on the electrical, thermal, and mechanical properties of PSS SiC ceramics.

\section{Experimental}

Commercially available a-SiC (0.5 $\mu \mathrm{m}$, Sintex 15C, Sika Tech, Fiven, Norway), $\beta-S i C(\sim 0.5 \mu \mathrm{m}$, BF17, H.C. Starck, Germany), $\mathrm{B}_{4} \mathrm{C}(0.5 \mu \mathrm{m}$, Kojundo Chemical Co., Ltd., Japan), and phenolic resin (TD-739, Kangnam Chemical Co., Ltd., Korea) were used as the starting materials. As shown in Table 1, the impurity contents obtained using inductively coupled plasma-optical emission spectroscopy (ICP-OES, OPTIMA 8300 DV, Perkin Elmer, USA) revealed a higher concentration of $\mathrm{Fe}$ and $\mathrm{V}$ impurities in $\beta$-SiC powders compared to a-SiC powders. The phenolic resin had a carbon yield of $60 \%$. As shown in Table 2, six batches of powders with varying initial a-SiC content $(0-100 \%$ of total $\mathrm{SiC})$ were prepared. The specimens were designated as $\mathrm{Ax}$, where ' $\mathrm{x}$ ' denotes the wt\% of $\mathrm{a}-\mathrm{SiC}$ phase in the total $\mathrm{SiC}$ content. $\mathrm{B}_{4} \mathrm{C}$ and $\mathrm{C}$ contents were fixed at 0.7 and $2.5 \mathrm{wt} \%$, respectively, in all batches. The batches were mixed using $\mathrm{SiC}$ balls by ball milling in ethanol with a ball to powder weight ratio of 2:1. After drying, the powder mixture was granulated using a 60-mesh sieve. The sieved powders were uniaxially pressed at $25 \mathrm{MPa}$ into both cylindrical ( $\varnothing 25 \mathrm{~mm} \times 7 \mathrm{~mm}$ high) and rectangular hexahedron $\left(40 \times 40 \times 4 \mathrm{~mm}^{3}\right)$ compacts, followed by cold isostatic pressing at $207 \mathrm{MPa}$. The green compacts were pyrolyzed at $900^{\circ} \mathrm{C}$ in flowing Ar gas for $1 \mathrm{~h}$ and subsequently pressureless sintered in a graphite resistance furnace at $2100^{\circ} \mathrm{C}$ for $2 \mathrm{~h}$ in flowing Ar gas. The theoretical and sintered densities were determined by the rule of mixtures and the weight-tovolume ratio of the sintered specimens, respectively. The polished specimens (up to $1 \mu \mathrm{m}$ ) were etched using a modified Murakami's reagent [41]. The details of microstructure characterization using SEM, phase analysis using XRD, electrical properties measurement using Hall effect, thermal conductivity measurement using laser flash method, flexural strength measurement using ASTM C 1161-13, fracture toughness measurement using JIS-R1607, and hardness measurement using Vickers indentation method are described elsewhere [35, 39, 42, 43].

\section{Table 1}


Impurity contents of $\alpha$ - and $\beta$-SiC starting powders obtained using inductively coupled plasma - optical emission spectroscopy (ICP-OES).

Impurity Impurity content (wt\%)
a-SiC
$\beta-S i C$
Table 2

\begin{tabular}{|c|c|c|c|c|c|}
\hline Al & 0.004 & 0.006 & \multirow{2}{*}{\multicolumn{3}{|c|}{$\begin{array}{l}\text { Batch composition, theoretical density, relative density, } \\
\text { and SiC polytype contents (determined by Rietveld } \\
\text { refinement method) of pressureless solid-state sintered } \\
\text { SiC ceramics. }\end{array}$}} \\
\hline $\mathrm{Fe}$ & 0.004 & 0.015 & & & \\
\hline $\mathrm{Ca}$ & 0.002 & 0.006 & \multirow[t]{2}{*}{ Impurity } & \multicolumn{2}{|c|}{ Impurity content (wt\%) } \\
\hline $\mathrm{Na}$ & 0.011 & 0.002 & & a-SiC & $\beta$-SiC \\
\hline \multirow[t]{6}{*}{ V } & \multirow[t]{6}{*}{0.001} & \multirow[t]{6}{*}{0.012} & Al & 0.004 & 0.006 \\
\hline & & & $\mathrm{Fe}$ & 0.004 & 0.015 \\
\hline & & & $\mathrm{Ca}$ & 0.002 & 0.006 \\
\hline & & & $\mathrm{Na}$ & 0.011 & 0.002 \\
\hline & & & V & 0.001 & 0.012 \\
\hline & & & \multicolumn{3}{|c|}{$\begin{array}{l}\text { Batch composition, theoretical density, relative density, } \\
\text { and SiC polytype contents (determined by Rietveld } \\
\text { refinement method) of pressureless solid-state sintered } \\
\text { SiC ceramics. }\end{array}$} \\
\hline
\end{tabular}

\section{Results And Discussion}

\subsection{Phase analysis and microstructure}

As shown in Table 2, all specimens had high relative densities ( $\geq 99 \%)$ when pressureless solid-state sintered at $2100^{\circ} \mathrm{C}$ for $2 \mathrm{~h}$ in flowing Ar gas using $0.7 \mathrm{wt} \% \mathrm{~B}_{4} \mathrm{C}$ and $2.5 \mathrm{wt} \% \mathrm{C}$ as sintering aids. The XRD patterns and $\mathrm{SiC}$ polytype contents in the sintered specimens are shown in Fig. 1 and Table 2, respectively. The XRD patterns revealed a-SiC $\left(6 \mathrm{H}, 4 \mathrm{H}, 15 \mathrm{R}\right.$ polytypes), and traces of $\mathrm{B}_{4} \mathrm{C}$ and graphite in the sintered specimens. $\beta$-SiC (3C) was not detected in the sintered specimens because of its complete conversion to a-phase caused by B-doping in the SiC lattice [38] and the high sintering temperature [44]. Residual $\mathrm{C}$ left after the carbothermal reduction of native $\mathrm{SiO}_{2}$ was transformed to graphite at the sintering temperature [5]. As shown in Table 2, $4 \mathrm{H}-\mathrm{SiC}$ content decreased with an increase in initial aphase content due to a slower $6 \mathrm{H}$ to $4 \mathrm{H}-\mathrm{SiC}$ phase transformation in a-SiC powders compared to $\beta$-SiC powders $[7,24-26]$. The $3 \mathrm{C}$ to $6 \mathrm{H}$ to $4 \mathrm{H}$ phase transformation was accelerated in the $\beta$-SiC powder due to its high thermodynamic instability at the sintering temperature and high Al content (refer to Table 2) [4547]. 
Typical microstructures of PSS SiC ceramics with varying initial a-phase content are shown in Fig. 2. The SEM micrographs exhibited a coarse-grained microstructure with elongated a-SiC platelet grains formed in situ via an accelerated $3 \mathrm{C}$ to $6 \mathrm{H}$ to $4 \mathrm{H}$ phase transformation in $\mathrm{A} 0$ and a gradual transformation to fine-grained microstructure with increasing initial a-phase content. The average aspect ratio of $\mathrm{SiC}$ grains decreased from $7.4 \pm 1.3$ in A0 to $2.9 \pm 0.4$ in A100. The fine-grained microstructure was responsible for the increased density $(99.1 \rightarrow 99.8 \%)$ with increasing initial a-phase content (refer to Table 2 ). It is well documented that equiaxed grains can easily accommodate each other and annihilate the residual pores, a phenomenon known as grain-shape-accommodation [29]. On the contrary, platelet grains grown preferentially along the c-axis hinder the elimination of inter-grain pores, due to interlocked elongated grains, resulting in a lower relative density.

\subsection{Electrical and thermal properties}

The electrical resistivity and carrier density of PSS SiC ceramics with varying initial a-phase content are shown in Fig. 3. The electrical resistivity monotonically decreased $\left(2.6 \times 10^{7} \rightarrow 1.5 \times 10^{6} \Omega \llbracket \mathrm{cm}\right)$ with increasing initial a-phase content presumably due to (1) a decreased bandgap energy with increasing $6 \mathrm{H}$-, $15 \mathrm{R}$ - and decreasing $4 \mathrm{H}-\mathrm{SiC}$ contents (refer to Table 2) and (2) the low impurity content of the a-SiC powders (Table 1). The high content of Fe and $\mathrm{V}$ impurities in $\beta$-SiC powders resulted in the donoracceptor compensation and trapping of charge carriers (refer to Table 1) [48], which is also indicated by an increase in carrier density $\left(1.1 \times 10^{10} \rightarrow 2.8 \times 10^{13} \mathrm{~cm}^{-3}\right)$ with increasing initial a-phase content (refer to Fig. 3). The bandgap energies of $6 \mathrm{H}, 15 \mathrm{R}$, and $4 \mathrm{H}$, are $3.10,2.98$, and $3.29 \mathrm{eV}$, respectively $[49,50]$. Various metallic and non-metallic impurities are known to affect the electrical properties of SiC ceramics $[48,51]$. Impurities like Al, B, Ga, and Sc are p-type dopants, whereas N, P, and Fe are n-type dopants. Both $\mathrm{n}$ - and p-type dopants increase the charge carrier density and thus decrease the electrical resistivity of SiC ceramics. However, in the case of codoping of $\mathrm{n}$ - and $\mathrm{p}$-type dopants, an acceptor-donor compensation takes place causing a decrease in the charge carrier density $[52,53]$. On the other hand, impurities like Be, $\mathrm{O}, \mathrm{V}$ tend to create a deep level within the bandgap trapping the charge carriers causing an increased electrical resistivity [53].

As shown in Table 3, the electrical resistivity of the solid-state sintered SiC ceramics could be tuned in the range of $10^{1}-10^{11} \Omega \llbracket \mathrm{cm}$ by changing the composition and sintering atmosphere [14, 17, 21, 54]. For example, PSS SiC ceramics with high electrical resistivities of $10^{8}-10^{11} \Omega \cdot \mathrm{cm}$ were fabricated by sintering in an $\mathrm{N}_{2}$ atmosphere at $\geq 2275^{\circ} \mathrm{C}$ and the high electrical resistivity was attributed to the formation of an electrically insulating C-B-N intergranular phase at grain boundaries [54]. On the other hand, the electrical resistivity of PSS SiC ceramics with $1 \mathrm{wt} \% \mathrm{~B}_{4} \mathrm{C}$ could be decreased $\left(10^{6} \rightarrow 10^{2} \Omega \llbracket \mathrm{cm}\right)$ by four orders of magnitude by adding $2 \mathrm{wt} \%$ electrically conductive graphene [21]. The ceramics in this study exhibited intermediate electrical resistivities $\left(10^{6}-10^{7} \Omega \cdot \mathrm{cm}\right)$ comparable to those of PSS SiC ceramics sintered with $1 \mathrm{wt} \% \mathrm{~B}_{4} \mathrm{C}$ at $2050^{\circ} \mathrm{C}$ in Ar gas [21]. As shown in Table 3, the reports on the electrical resistivity of PSS SiC ceramic sintered with $\beta$-SiC powders are rarely found, presumably due to their higher cost and lower stability at high sintering temperatures compared to a-SiC powders. This study 
revealed that the high thermodynamic instability of $\beta$-SiC powders can be used to tune the electrical properties of PSS SiC ceramics to some extent via a controlled $3 \mathrm{C}$ to $6 \mathrm{H}$ to $4 \mathrm{H}$ phase transformation.

Table 3

Starting powder polytype, processing conditions, relative density, electrical resistivity, and thermal conductivity of solid-state sintered SiC ceramics.

\begin{tabular}{|c|c|c|c|c|c|c|}
\hline \multirow[t]{2}{*}{ Specimen } & \multirow[t]{2}{*}{ Batch composition (wt\%) } & \multirow[t]{2}{*}{$\begin{array}{l}\text { Theoretical } \\
\text { density }\left(\mathrm{g} / \mathrm{cm}^{3}\right)\end{array}$} & \multirow{2}{*}{$\begin{array}{l}\text { Relative } \\
\text { density } \\
(\%)\end{array}$} & \multicolumn{3}{|c|}{$\begin{array}{l}\text { SiC polytype } \\
\text { content (\%) }\end{array}$} \\
\hline & & & & $6 \mathrm{H}$ & $4 \mathrm{H}$ & $15 R$ \\
\hline \multirow[t]{2}{*}{ AO } & $96.80 \% \beta-S i C+2.5 \% C$ & 3.174 & 99.1 & 75.3 & 24.7 & 0.0 \\
\hline & $+0.7 \% \mathrm{~B}_{4} \mathrm{C}$ & & & & & \\
\hline A20 & $\begin{array}{l}19.36 \% a-S i C+77.44 \% \beta-S i C+ \\
2.5 \% C+0.7 \% B_{4} C\end{array}$ & 3.174 & 99.0 & 76.8 & 22.4 & 0.8 \\
\hline A40 & $\begin{array}{l}38.72 \% \text { a-SiC }+58.08 \% \beta-S i C+ \\
2.5 \% \mathrm{C}+0.7 \% \mathrm{~B}_{4} \mathrm{C}\end{array}$ & 3.174 & 99.6 & 78.6 & 19.9 & 1.5 \\
\hline A60 & $\begin{array}{l}58.08 \% \text { a-SiC }+38.72 \% \beta-S i C+ \\
2.5 \% \mathrm{C}+0.7 \% \mathrm{~B}_{4} \mathrm{C}\end{array}$ & 3.174 & 99.7 & 82.3 & 15.4 & 2.3 \\
\hline A80 & $\begin{array}{l}77.4 \% \mathrm{a}-\mathrm{SiC}+19.36 \% \beta-\mathrm{SiC}+ \\
2.5 \% \mathrm{C}+0.7 \% \mathrm{~B}_{4} \mathrm{C}\end{array}$ & 3.174 & 99.7 & 84.8 & 12.3 & 2.9 \\
\hline \multirow[t]{2}{*}{ A100 } & $96.80 \% a-S i C+2.5 \% \mathrm{C}$ & 3.174 & 99.8 & 85.5 & 9.8 & 4.7 \\
\hline & $+0.7 \% \mathrm{~B}_{4} \mathrm{C}$ & & & & & \\
\hline
\end{tabular}

The thermal conductivity of PSS SiC ceramics with varying initial a-phase content is shown in Fig. 4. The thermal conductivity monotonically increased from $117.1 \mathrm{Wm}^{-1} \mathrm{~K}^{-1}$ in $\mathrm{A} 0$ to $154.2 \mathrm{Wm}^{-1} \mathrm{~K}^{-1}$ in $\mathrm{A} 100$ due to (1) an increased $6 \mathrm{H}-\mathrm{SiC}$ content, which has a higher intrinsic thermal conductivity compared to that of $4 \mathrm{H}-\mathrm{SiC}$ [38] and (2) the low soluble impurity content of the a-SiC starting powders (refer to Table 1). Soluble impurities, such as Fe and $\mathrm{V}[55,56]$, act as phonon scattering sites in the SiC lattice and deteriorate the thermal conductivity. As shown in Table 3, the reported thermal conductivity of solid-state sintered SiC ceramics varies from 107 to $192 \mathrm{Wm}^{-1} \mathrm{~K}^{-1}$ depending on the composition and processing conditions. Li et al. [12] reported a high thermal conductivity of $192.2 \mathrm{Wm}^{-1} \mathrm{~K}^{-1}$ attributed to an optimum content of sintering aids ( $0.4 \mathrm{wt} \% \mathrm{~B}_{4} \mathrm{C}$ and $3 \mathrm{wt} \% \mathrm{C}$ ) derived from polymeric precursors. However, a low thermal conductivity of $107 \mathrm{Wm}^{-1} \mathrm{~K}^{-1}$ was reported for SiC- $5 \mathrm{wt} \%$ graphene composite attributed to an increased interfacial thermal resistance at SiC-graphene heterogeneous interfaces [14]. As shown in Table 3, the literature is limited to the thermal conductivity of PSS SiC ceramics started with a-SiC powders. This study revealed that $\beta$-SiC powders are detrimental to thermal conductivity because they 
promote $6 \mathrm{H}$ to $4 \mathrm{H}$ phase transformation, leading to an increase of $4 \mathrm{H}$ phase, which has a low intrinsic thermal conductivity compared to $6 \mathrm{H}$ phase.

Based on the above discussion, the thermal conductivity of PSS SiC ceramics can be improved by (1) minimizing the content of sintering additives and secondary phases, (2) using high purity starting powders, and (3) avoiding or minimizing $6 \mathrm{H}$ to $4 \mathrm{H}$ phase transformation during sintering.

\subsection{Mechanical properties}

The mechanical properties of PSS SiC ceramics with varying initial a-phase content are shown in Table 4. The flexural strength $\left(\sigma_{f}\right)$ increased from $289.5 \mathrm{MPa}$ in A0 to $335.1 \mathrm{MPa}$ in A100 attributed to a decreased defect size with decreasing grain size $[11,13,24,57]$. However, the fracture toughness $\left(K_{I C}\right)$ and hardness were almost constant at 2.2-2.3 MPa $\triangle \mathrm{m}^{1 / 2}$ and approximately $28 \mathrm{GPa}$, respectively, with the variation in initial a-SiC content. As shown in Fig. 5 , the crack path did not exhibit any active crack-microstructure interaction due to strong interfacial bonding between the $\mathrm{SiC}$ grains, leading to a predominant transgranular fracture in all specimens (refer to Fig. 6). In the absence of active crack-microstructure interaction, the fracture toughness was insensitive to changes in microstructure. These results are consistent with the findings of Magnani et al. [11] (refer to Table 5). It was demonstrated that fine-grained PSS SiC ceramics fabricated via two-step sintering exhibited 39\% higher flexural strength compared to the coarse-grained ceramics fabricated via a conventional sintering process [11]. However, the fracture toughness and hardness did not exhibit any significant change [11]. As shown in Table 4, the calculated critical flaw sizes $(c, 26-35 \mu \mathrm{m})$ were larger than the average grain sizes implying that the fracture had originated from processing defects. The critical flaw sizes were calculated using the equation $K_{I C}=1.35$ $\sigma_{f} c^{1 / 2}$, assuming semielliptical surface flaws [24]. Figure 7 shows the typical fracture origins of PSS SiC ceramics which were mostly residual pores near the surface. The critical flaw sizes of A0 and A100 observed in Fig. 7 are comparable to the sizes calculated (Table 4). A decreased critical flaw size with increasing initial a-phase content indicates a superior sinterability of a-SiC compared to $\beta$-SiC powders, which is also indicated by a decreased scatter in flexural strength values with the addition of a-SiC powders (refer to Table 4). 
Table 4

Flexural strength, fracture toughness, hardness, and calculated flaw size of pressureless solid-state sintered SiC ceramics.

\begin{tabular}{|c|c|c|c|c|c|}
\hline Reference & $\begin{array}{l}\text { Starting } \\
\text { powder }\end{array}$ & $\begin{array}{l}\text { Processing } \\
\text { conditions }\end{array}$ & $\begin{array}{l}\text { Relative density (\%)/ } \\
\text { sintering aid (wt\%) }\end{array}$ & $\begin{array}{l}\text { Electrical } \\
\text { resistivity } \\
(\Omega \bowtie c m)\end{array}$ & $\begin{array}{l}\text { Thermal } \\
\text { conductivity } \\
\left(\mathrm{Wm}^{-1} \mathrm{~K}^{-1}\right)\end{array}$ \\
\hline $\begin{array}{l}\text { Munro et } \\
\text { al. [4] }\end{array}$ & $a-S i C$ & $2500^{\circ} \mathrm{C}$ & $98 / B+C$ & - & 114 \\
\hline $\begin{array}{l}\text { Li et al. } \\
{[14]}\end{array}$ & $\mathrm{a}-\mathrm{SiC}$ & $2130^{\circ} \mathrm{C} / 1 \mathrm{~h} / \mathrm{Ar}$ & $\begin{array}{l}96.7-99.2 / 1 \% \mathrm{~B}_{4} \mathrm{C} \\
+3.2 \% \mathrm{C}+0-5 \% \\
\text { graphene }\end{array}$ & $\begin{array}{l}5.6 \times 10^{1}- \\
5.0 \times 10^{2}\end{array}$ & $107-145$ \\
\hline $\begin{array}{l}\text { Li et al. } \\
\text { [12] }\end{array}$ & $a-S i C$ & $\begin{array}{l}2150^{\circ} \mathrm{C} / 1 \mathrm{~h} \rightarrow \\
1950^{\circ} \mathrm{C} / 4 \mathrm{~h} / \mathrm{Ar}\end{array}$ & $\begin{array}{l}99.4 / 0.4 \% B+0.4 \% \\
C\end{array}$ & - & 192.2 \\
\hline $\begin{array}{l}\text { Taki et al. } \\
\text { [17] }\end{array}$ & $a-S i C$ & $\begin{array}{l}\text { SPS: } 2100^{\circ} \mathrm{C} / 50 \\
\mathrm{MPa} / 5 \mathrm{~min} / \\
\text { vacuum or } \mathrm{N}_{2}\end{array}$ & $97 / 1-5 \mathrm{~mol} \% \mathrm{~B}$ & $10^{3}-10^{4}$ & $132-185$ \\
\hline \multirow[t]{2}{*}{$\begin{array}{l}\text { Cai et al. } \\
\text { [21] }\end{array}$} & - & $2050^{\circ} \mathrm{C} / 2 \mathrm{~h} / \mathrm{Ar}$ & $97.7 / 1 \% \mathrm{~B}_{4} \mathrm{C}$ & $>10^{6}$ & \\
\hline & & & $\begin{array}{l}96.7 / 1 \% \mathrm{~B}_{4} \mathrm{C}+2 \% \\
\text { graphene }\end{array}$ & $1.9 \times 10^{2}$ & - \\
\hline $\begin{array}{l}\text { Boecker } \\
\text { et al. [54] }\end{array}$ & $\mathrm{a}-\mathrm{SiC}$ & $2300^{\circ} \mathrm{C} / 2 \mathrm{~h} / \mathrm{N}_{2}$ & $99.3 / 1 \% B_{4} C+1 \% C$ & $10^{8}-10^{11}$ & - \\
\hline \multirow[t]{2}{*}{$\begin{array}{l}\text { This } \\
\text { study }\end{array}$} & $\mathrm{a}-\mathrm{SiC}$ & $2100^{\circ} \mathrm{C} / 2 \mathrm{~h} / \mathrm{Ar}$ & $>99 / 0.7 \% \mathrm{~B}_{4} \mathrm{C}+2.5 \% \mathrm{C}$ & $1.5 \times 10^{6}$ & 154.2 \\
\hline & $\beta-S i C$ & & & $2.6 \times 10^{7}$ & 117.1 \\
\hline
\end{tabular}


Table 5

Starting powder polytype, processing conditions, relative density, sintering aid composition, and mechanical properties of pressureless solid-state sintered SiC ceramics. ISB, IF, and SENB denote indentation strength in bending, indentation fracture, and single edge notched beam, respectively. * denotes the flexural strength measured using a three-point bending method.

\begin{tabular}{|lllll|}
\hline Specimen & $\begin{array}{l}\text { Flexural strength } \\
(\mathrm{MPa})\end{array}$ & $\begin{array}{l}\text { Fracture toughness } \\
\left(\mathrm{MPa} \mathbf{m}^{1 / 2}\right)\end{array}$ & $\begin{array}{l}\text { Hardness } \\
(\mathrm{GPa})\end{array}$ & $\begin{array}{l}\text { Calculated critical flaw } \\
\text { size }(\boldsymbol{\mu m})\end{array}$ \\
\hline $\mathrm{A} 0$ & $289.5 \pm 45.6$ & $2.3 \pm 0.1$ & $28.1 \pm 1.2$ & 35 \\
\hline $\mathrm{A} 20$ & $300.3 \pm 42.7$ & $2.2 \pm 0.1$ & $28.8 \pm 2.8$ & 29 \\
\hline $\mathrm{A} 40$ & $308.8 \pm 35.9$ & $2.2 \pm 0.1$ & $28.2 \pm 2.8$ & 28 \\
\hline A60 & $316.7 \pm 42.2$ & $2.2 \pm 0.1$ & $28.0 \pm 3.0$ & 26 \\
\hline A80 & $330.7 \pm 50.4$ & $2.3 \pm 0.1$ & $27.8 \pm 1.4$ & 27 \\
\hline A100 & $335.1 \pm 23.9$ & $2.3 \pm 0.1$ & $28.4 \pm 2.6$ & 26 \\
\hline $\begin{array}{l}\text { Starting powder polytype, processing conditions, relative density, sintering aid composition, and } \\
\text { mechanical properties of pressureless solid-state sintered SiC ceramics. ISB, IF, and SENB denote } \\
\text { indentation strength in bending, indentation fracture, and single edge notched beam, respectively. * } \\
\text { denotes the flexural strength measured using a three-point bending method. }\end{array}$ \\
\hline
\end{tabular}

As shown in Table 5, the reported flexural strength, fracture toughness, and hardness of PSS SiC ceramics vary from 312-556 MPa, 2.5-5.7 MPa $\triangle \mathrm{m}^{1 / 2}$, and 21.2-30.2 $\mathrm{GPa}$, respectively $[6,10,11,13,15$, 16]. A wide distribution of flexural strength is due to the difference in composition, processing conditions and measurement methods among the various works. According to Biswas's work [9] on the flexural strength of hot-pressed $\mathrm{SiC}$ ceramics sintered with $\mathrm{Al}-\mathrm{B}-\mathrm{C}$ additives, the flexural strength measured using the three-point bending method was approximately $150 \mathrm{MPa}$ higher than that obtained using the four-point bending method. Thus, the flexural strength values (289-335 MPa) of the present specimens measured by four-point bending are estimated to be superior to those (312-435 MPa, three-point bending) of PSS SiC ceramics with 0.5-1 wt\% $B_{4} C$ and 3.1-4.7 wt\% $C[10,15,16]$. Magnani et al. $[11,13]$ reported high flexural strengths of 530-556 MPa for two-step sintered SiC ceramics with fine-grained microstructure compared to those (320-467 MPa) of PSS SiC ceramics with coarse-grained microstructures reported in other works $[3,4,6,15,16]$. A fine-grained microstructure is beneficial in improving flexural strength because of the reduced critical flaw size [11, 13]. As shown in Table 5, the previous works were limited to the flexural strength of PSS SiC ceramics sintered with a-SiC powders. This study revealed that $\beta$-SiC powders promote abnormal growth of platelet grains via an in situ $3 \mathrm{C}$ to $6 \mathrm{H}$ to $4 \mathrm{H}$ phase transformation, leading to increased flaw size and reduced flexural strength. A direct comparison of fracture toughness values in the literature is difficult because the fracture toughness (2.54.6 $\mathrm{MPa} \triangle \mathrm{m}^{1 / 2}$ ) was measured using various methods such as indentation strength in bending (ISB), single edge notched beam (SENB), and indentation fracture (IF). According to Rudnayova et al.'s work [58] on the fracture toughness of hot pressed $\mathrm{Si}_{3} \mathrm{~N}_{4}$ ceramics measured using IF, ISB, and SENB methods, the fracture toughness varied by $3 \mathrm{MPa} \llbracket \mathrm{m}^{1 / 2}$ depending on the method and indentation load. Nonetheless, 
the literature $[11,15]$ revealed that the low fracture toughness of PSS SiC ceramics is attributed to a strong interfacial bonding between the SiC grains, leading to a poor crack-microstructure interaction. Li et al.'s work [16] on PSS SiC ceramics with $0-5 \mathrm{wt} \%$ graphene suggests that the fracture toughness could be improved by adding graphene to promote crack deflection at SiC-graphene interfaces. The newly developed PSS SiC ceramics exhibited high hardness $(28.4 \mathrm{GPa})$ comparable to the highest reported values $(27.3-30.2 \mathrm{GPa})$.

Based on the above discussion, high flexural strength in PSS SiC ceramics can be obtained by (1) using a-SiC starting powders to ensure a fine-grained microstructure with reduced flaw size, (2) optimizing the sintering cycle to avoid undesirable grain growth, and (3) avoiding an in situ $6 \mathrm{H}$ to $4 \mathrm{H}$ phase transformation causing abnormal grain growth. The fracture toughness of PSS SiC ceramics can be improved by adding secondary phases such as graphene, which results in weak heterogeneous interfaces and promotes crack deflection along the grain boundaries $[16,19]$.

\section{Conclusions}

SiC ceramics with 0 to $100 \%$ initial a-phase content were densified to high relative densities ( $\geq 99 \%)$ via pressureless solid-state sintering with $0.7 \mathrm{wt} \% \mathrm{~B}_{4} \mathrm{C}$ and $2.5 \mathrm{wt} \% \mathrm{C}$ at $2100^{\circ} \mathrm{C}$ in flowing Ar gas. The major findings are summarized as follows:

1. The phase analysis revealed an increased $6 \mathrm{H}-\mathrm{SiC}$ content with increasing initial a-phase due to a slower $6 \mathrm{H}$ to $4 \mathrm{H}-\mathrm{SiC}$ phase transformation in a-SiC powders compared to $\beta$-SiC powders.

2. a-SiC starting powders exhibited a fine-grained microstructure with platelet grains of low aspect ratio (2.9) whereas $\beta$-SiC powders exhibited a coarse-grained microstructure with elongated platelet grains of high aspect ratio (7.4), which formed in situ via an accelerated $3 \mathrm{C}$ to $6 \mathrm{H}$ to $4 \mathrm{H}$ phase transformation of $\mathrm{SiC}$.

3. The electrical resistivity monotonically decreased from $2.6 \times 10^{7}$ to $1.5 \times 10^{6} \Omega \llbracket \mathrm{cm}$ with increasing initial a-phase content from 0 to $100 \%$ attributed to (1) an increased $6 \mathrm{H}-\mathrm{SiC}$ content causing a decrease in bandgap energy and (2) the low soluble impurity content (Fe and V) of the a-SiC powders. The high content of $\mathrm{Fe}$ and $\mathrm{V}$ impurities in $\beta$-SiC powders resulted in the donor-acceptor compensation and trapping of charge carriers.

4. The thermal conductivity monotonically increased from 117.1 to $154.2 \mathrm{Wm}^{-1} \mathrm{~K}^{-1}$ with increasing initial a-phase content from 0 to $100 \%$ due to (1) an increased $6 \mathrm{H}$-SiC content with a high intrinsic thermal conductivity and (2) the low impurity content of the a-SiC powders.

5. Flexural strength increased $(289.5 \rightarrow 335.1 \mathrm{MPa})$ with increasing initial a-phase content due to decreased flaw size with decreasing grain size. Fracture toughness $\left(2.2-2.3 \mathrm{MPa} \cdot \mathrm{m}^{1 / 2}\right)$ and hardness ( $₫ 28 \mathrm{GPa}$ ) were insensitive to the change in microstructure with varying initial a-phase content.

\section{Declarations}




\section{Acknowledgment}

This work was supported by the World Class 300 Project (R\&D) (P0013001, Development of Localization Technology for Pressureless Sintered, Electrical Resistivity Controlled $(0.1 \sim 30 \Omega \llbracket \mathrm{cm}) 10 \mathrm{~nm}$ Semiconductor-grade New-SiC without Free-Si, and CVD-SiC coated New-SiC ) of the MOTIE, MSS (Korea).

\section{References}

1. Prochazka S (1975) Sintering of silicon carbide. In Mass transport phenomena in ceramics, Materials Science Research, vol 9. Cooper AR, Heuer AH, Eds. Boston: Springer, 421-431

2. Prochazka S, Scanlan RM (1975) Effect of boron and carbon on sintering of SiC. J Am Ceram Soc $58: 72$

3. Hurst JB, Dutta S. Simple processing method for high-strength silicon carbide. J Am Ceram Soc 1987, 70: C-C303-308

4. Munro RG (1997) Material properties of a sintered a-SiC. J Phys Chem Ref Data 26:1195-1203

5. Hamminger R (1989) Carbon Inclusions in Sintered Silicon Carbide. J Am Ceram Soc 72:1741-1744

6. Magnani G, Beltrami G, Minoccari GL et al (2011) Presureless sintering and properties of aSiC- $B_{4} C$ composite. J Eur Ceram Soc 21:633-638

7. Yoshimura HN, Cruz ACD, Zhou $Y$ et al (2002) Sintering of $6 \mathrm{H}(\mathrm{a})-\mathrm{SiC}$ and $3 \mathrm{C}(\beta)-\mathrm{SiC}$ powders with $\mathrm{B}_{4} \mathrm{C}$ and $\mathrm{C}$ additives. J Mater Sci 37:1541-1546

8. Balog M, Sajgalik P, Hnatko M et al (2005) Nano-versus macro-hardness of liquid phase sintered SiC. J Eur Ceram Soc 25:529-534

9. Biswas K (2009) Solid state sintering of SiC-ceramics. Mater Sci Forum 624:71-89

10. Chen $Y$, Jiang L, Jia X (2011) Properties of pressureless sintered SiC-TiB ${ }_{2}$ composites. Adv Mater Res 177:369-372

11. Magnani G, Brentari A, Burresi E et al (2014) Pressureless sintered silicon carbide with enhanced mechanical properties obtained by the two-step sintering method. Ceram Int 40:1759-1763

12. Li Y, Yin J, Wu H et al (2014) High thermal conductivity in pressureless densified SiC ceramics with ultra-low contents of additives derived from novel boron-carbon sources. J Eur Ceram Soc 34:25912595

13. Magnani G, Sico G, Brentari A et al (2014) Solid-state pressureless sintering of silicon carbide below $2000^{\circ} \mathrm{C}$. J Eur Ceram Soc 34:4095-4098

14. Li Q, Zhang Y, Gong H et al (2015) Effects of graphene on the thermal conductivity of pressurelesssintered SiC ceramics. Ceram Int 41:13547-13552

15. Wu H, Yan Y, Liu G et al (2015) Effects of grain grading on microstructures and mechanical behaviors of pressureless solid-state-sintered SiC. Int J Appl Ceram Technol 12:976-984 
16. Li Q, Zhang Y, Gong H et al (2016) Enhanced fracture toughness of pressureless-sintered SiC ceramics by addition of graphene. J Mater Sci Technol 32:633-638

17. Taki Y, Kitiwan M, Katsui H et al (2019) Effect of B doping on electrical and thermal properties of SiC bodies fabricated by spark plasma sintering. Mater Today: Proc 16:211-215

18. Kim YW, Kultayeva S, Sedlacek J et al (2020) Thermal and electrical properties of additive-free rapidly hot-pressed SiC ceramics. J Eur Ceram Soc 40:234-240

19. Hanzel O, Lences Z,. Kim YW (2020) Highly electrically and thermally conductive silicon carbidegraphene composites with yttria and scadia additives. J Eur Ceram Soc 40:241-250

20. Li Y, Lao X, Wang T et al (2020) Effects of aggregate/matrix-phase ratio on the in-situ synthesis of $\mathrm{SiC}$ whiskers and properties of reaction-bonded SiC. Int J Appl Ceram Technol 17:2147-2155

21. Cai N, Guo D, Wu G et al (2020) Decreasing resistivity of silicon carbide ceramics by incorporation of graphene. Materials 13:3586

22. Dey A, Kayal N, Chakrabarti O et al (2021) Studies on processing of layered oxide-bonded porous SiC ceramic filter materials. Int J Appl Ceram Technol 18:869-879

23. Greskovich C, Rosolowski JH (1976) Sintering of covalent solids. J Am Ceram Soc 59:336-343

24. Kim YW, Mitomo M, Emoto $\mathrm{H}$ et al (1998) Effect of initial a-phase content on microstructure and mechanical properties of sintered silicon carbide. J Am Ceram Soc 81:3136-3140

25. Nader M, Aldinger F,. Hoffmann MJ (1999) Influence of the $\alpha / \beta$-SiC phase transformation on microstructural development and mechanical properties of liquid phase sintered silicon carbide. $J$ Mater Sci 34:1197-1204

26. Zhou $Y$, Tanaka H, Otani S et al (1999) Low-temperature pressureless sintering of alpha-SiC with $\mathrm{Al}_{4} \mathrm{C}_{3}-\mathrm{B}_{4} \mathrm{C}-\mathrm{C}$ additions. J Am Ceram Soc 82:1959-1964

27. Maity T, Kim YW. High-temperature strength of liquid-phase-sintered SiC ceramics: a review. Int J Appl Ceram Technol. In press

28. Biswas K, Rixecker G, Wiedmann I et al (2001) Liquid phase sintering and microstructure-property relationships of silicon carbide ceramics with oxynitride additives. Mater Chem Phys 67:180-191

29. German RM, Suri P, Park SJ (2009) Review: liquid phase sintering. J Mater Sci 44:1-39

30. Biswas K, Rixecker G, Aldinger F (2005) Gas pressure sintering of SiC sintered with rare-earth-(III)oxides and their mechanical properties. Ceram Int 31:703-711

31. Zhang C, Yao X, Li Y et al (2015) Effect of AlN addition on the thermal conductivity of pressureless sintered SiC ceramics. Ceram Int 41:9107-9114

32. Liang $\mathrm{H}$, Yao X, Zhang $\mathrm{J}$ et al (2014) Low temperature presureless sintering of $\mathrm{a}$-SiC with $\mathrm{Al}_{2} \mathrm{O}_{3}$ and $\mathrm{CeO}_{2}$ as additives. $\mathrm{J}$ Eur Ceram Soc 34:831-835

33. Zhang J, Iwasa M, Jiang $\mathrm{D}$ (2005) Dispersion of $\mathrm{SiC}$ in aqueous media with $\mathrm{Al}_{2} \mathrm{O}_{3}$ and $\mathrm{Y}_{2} \mathrm{O}_{3}$ as sintering additives. J Am Ceram Soc 88:1013-1016

34. Magnani G, Galvagno S, Sico G et al (2016) Sintering and mechanical properties of $\beta$-SiC powder obtained from waste tires. J Adv Ceram 5:40-46 
35. Kim KJ, Malik R, Park J et al (2020) Effects of $\mathrm{M}_{2} \mathrm{O}_{3}-\mathrm{Y}_{2} \mathrm{O}_{3}(\mathrm{M}=\mathrm{Sc}$ and Al) additives on electrical conductivity of hot-pressed SiC ceramics. Ceram Int 46:5454-5458

36. Yu Z, Lv X, Mao K et al (2020) Role of in-situ formed free carbon on electromagnetic absorption properties of polymer-derived SiC ceramics. J Adv Ceram 9:617-628

37. He R, Zhou N, Zhang K et al (2021) Progress and challenges towards additive manufacturing of SiC ceramics. J Adv Ceram 10:637-674

38. Kim YW, Malik R (2020) SiC ceramics, structure, processing, and properties. In: Pomeroy M (ed) Encyclopedia of materials: technical ceramics and glasses, vol 2. Elsevier, Amsterdam, pp 150-164

39. Malik R, Kim YW (2021) Plastic deformation-induced improved mechanical and thermal properties in hot-forged SiC-TiC composite. J Eur Ceram Soc 41:213-224

40. Malik R, Kim YW. Pressureless solid-state sintering of SiC ceramics with $\mathrm{BN}$ and $\mathrm{C}$ additives. $J$ Asian Ceram Soc. In press

41. Yasar ZA, Haber RA (2020) Effect of carbon addition and mixture method on the microstructure and mechanical properties of silicon carbide. Materials 13:3768

42. Cho TY, Malik R, Kim YW et al (2018) Electrical and mechanical properties of pressureless sintered $\mathrm{SiC}-\mathrm{Ti}_{2} \mathrm{CN}$ composites. J Eur Ceram Soc 38:3064-3072

43. Kim YH, Kim YW, Kim KJ (2019) Electrically conductive SiC ceramics processed by pressureless sintering. Int J Appl Ceram Technol 16:843-849

44. Yoo WS, Nishino S, Matsunami H (1989) Polytype change of silicon carbide at high temperatures. In Amorphous and crystalline silicon carbide II, Springer proceedings in physics, vol 43. Rahman MM, Yang CYW, Harris GL, Eds. Berlin: Springer, 35-39

45. Tanaka H, Hirosaki N, Nishimura T et al (2003) Nonequiaxial grain growth and polytype transformation of sintered a-silicon carbide and $\beta$-silicon carbide. J Am Ceram Soc 86:2222-2224

46. Scalise E, Marzegalli A, Montalenti F et al (2019) Temperature-dependent stability of polytypes and stacking faults in SiC: reconciling theory and experiments. Phys Rev Appl 12:021002

47. Jepps NW, Page TF (1983) Polytypic transformations in silicon carbide. Prog Cryst Growth Charact 7:259-307

48. Kim KJ, Kim YW (2012) Fe doping and magnetic properties of zincblende SiC ceramics. J Eur Ceram Soc 32:1149-1155

49. Persson C, Lindefelt U (1997) Relativistic band structure calculation of cubic and hexagonal SiC polytypes. J Appl Phys 82:5496-5508

50. Zhang FC, Gao Y, Cui HW et al (2014) First-principles study on electronic structure of 15R-SiC polytypes. Adv Mater Res 971-973:77-80

51. Kim YW, Tochigi E, Tatami J et al (2019) Carrier depletion near the grain boundary of a SiC bicrystal. Sci Rep 9:18014

52. Kim KJ, Lim KY, Kim YW (2013) Control of electrical resistivity in silicon carbide ceramics sintered with aluminum nitride and yttria. J Am Ceram Soc 96:3463-3469 
53. Kim YW, Kim YH, Kim KJ (2020) Electrical properties of liquid-phase sintered silicon carbide ceramics: a review. Crit Rev Solid State 45:66-84

54. Boecker DGW, Hailey LN, McMurtry CH. Sintered silicon carbide ceramic body of high electrical resistivity. U.S. patent 4701427 , Oct. 1985

55. Inai H, Satoh Y, Okamoto Y et al (1999) Thermoelectric properties of Fe doped SiC ceramics. J Adv Sci 11:188-192

56. Kultayeva S, Kim YW, Song IH (2021) Effects of dopants on electrical, thermal, and mechanical properties of porous SiC ceramics. J Eur Ceram Soc 41:4006-4015

57. Seidel J, Claussen N, Rödel J (1995) Reliability of alumina ceramics: effect of grain size. J Eur Ceram Soc 15:395-404

58. Rudnayova E, Dusza J, Kupkova M (1993) Comparison of fracture toughness measuring methods applied on silicon nitride ceramics. J Phys IV 3:1273-1276

\section{Figures}

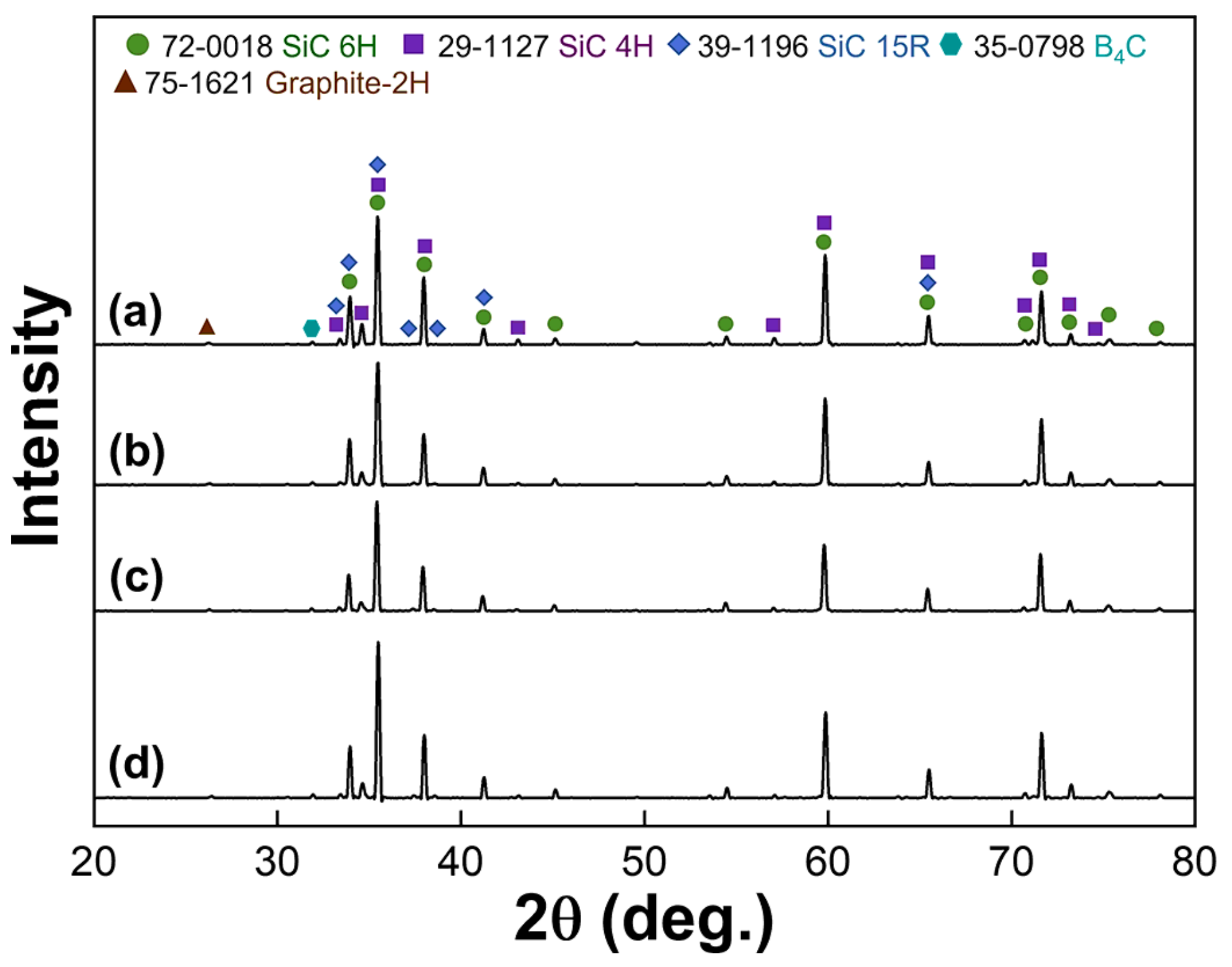




\section{Figure 1}

XRD patterns of pressureless solid-state sintered $\mathrm{SiC}$ ceramics with varying initial a-phase content: (a) A0, (b) A40, (c) A80, and (d) A100 (refer to Table 2).
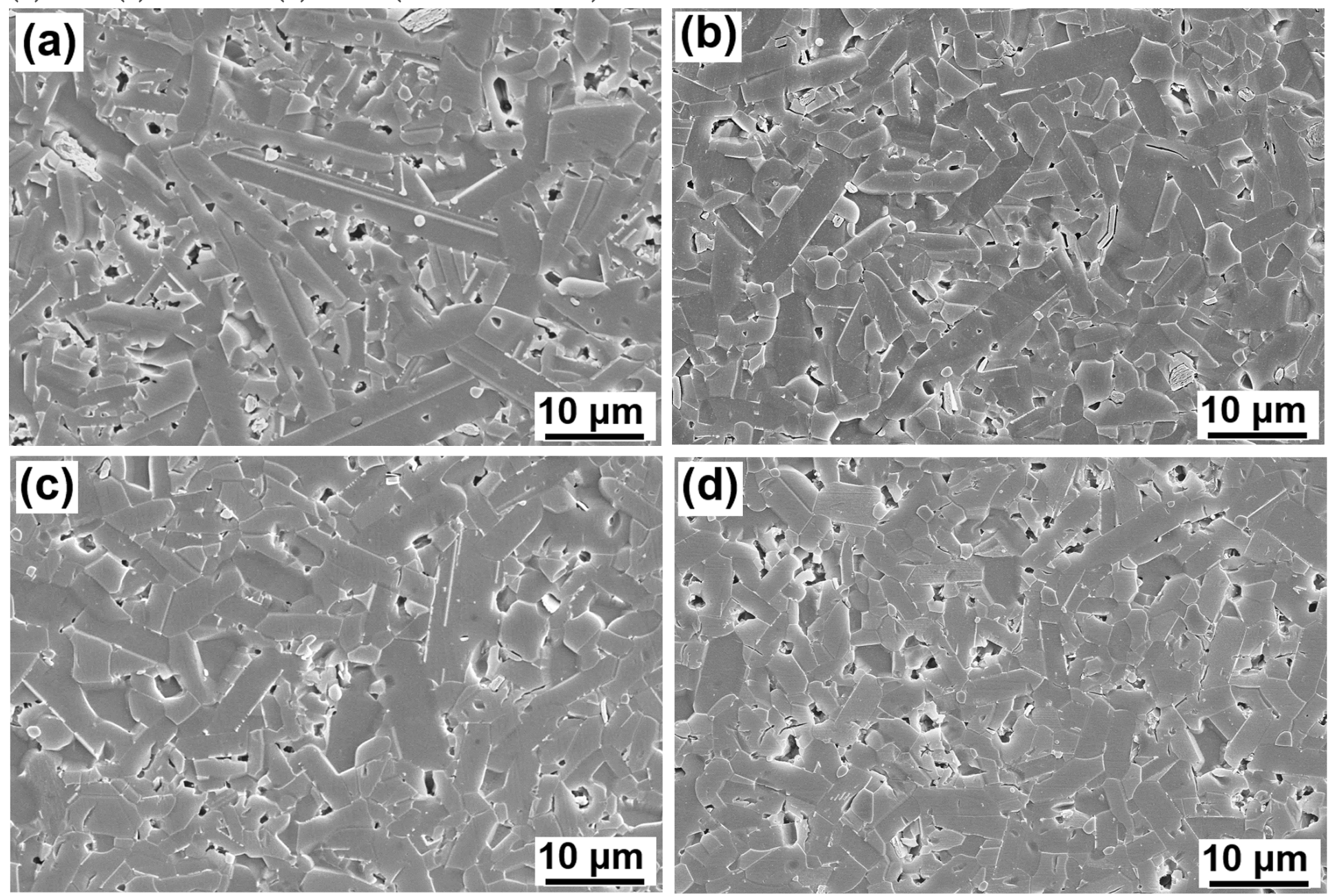

\section{Figure 2}

Typical microstructures of pressureless solid-state sintered SiC ceramics with varying initial a-phase content: (a) A0, (b) A40, (c) A80, and (d) A100. 


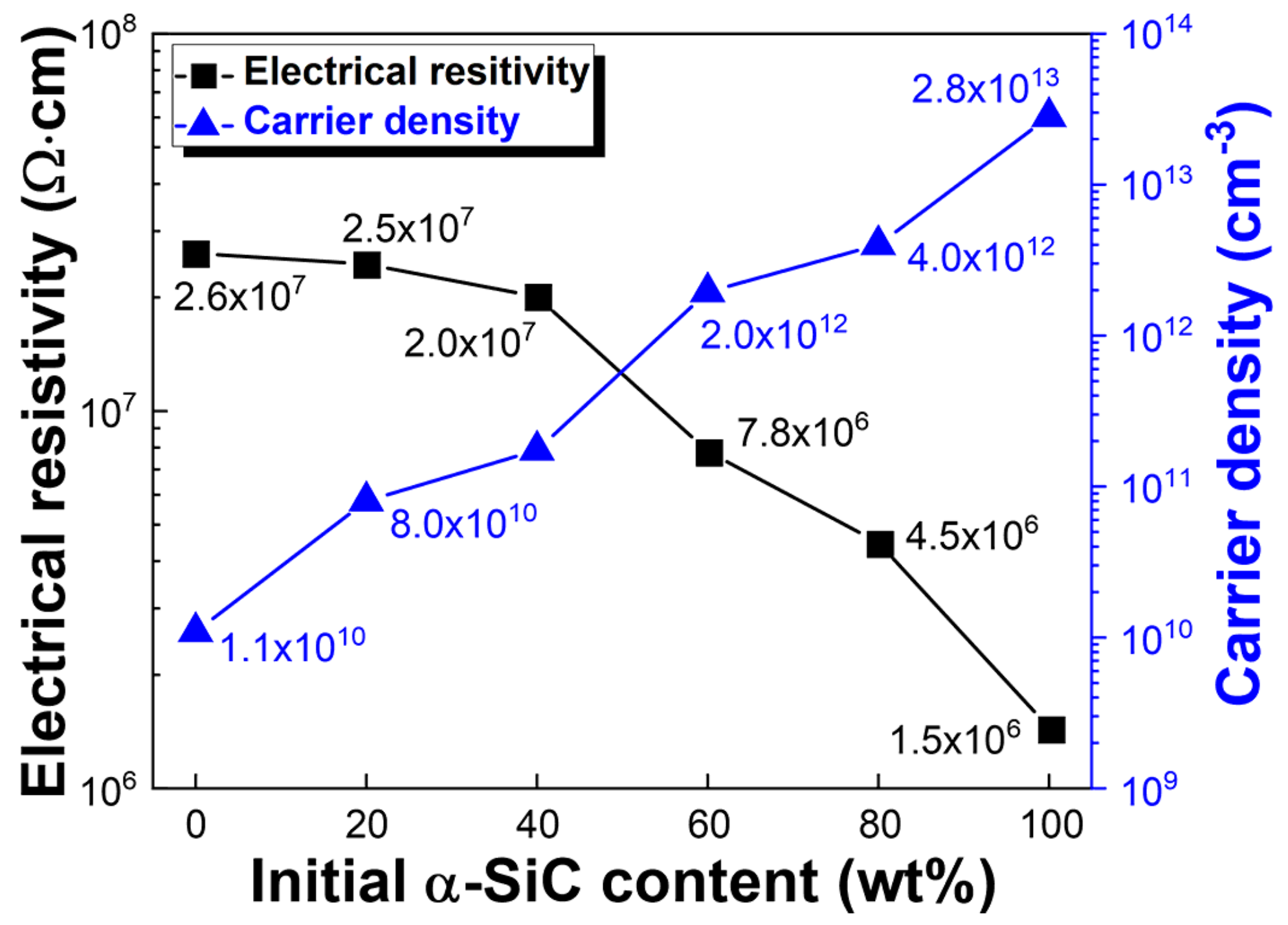

Figure 3

Electrical resistivity and carrier density of pressureless solid-state sintered SiC ceramics with varying initial a-phase content. 


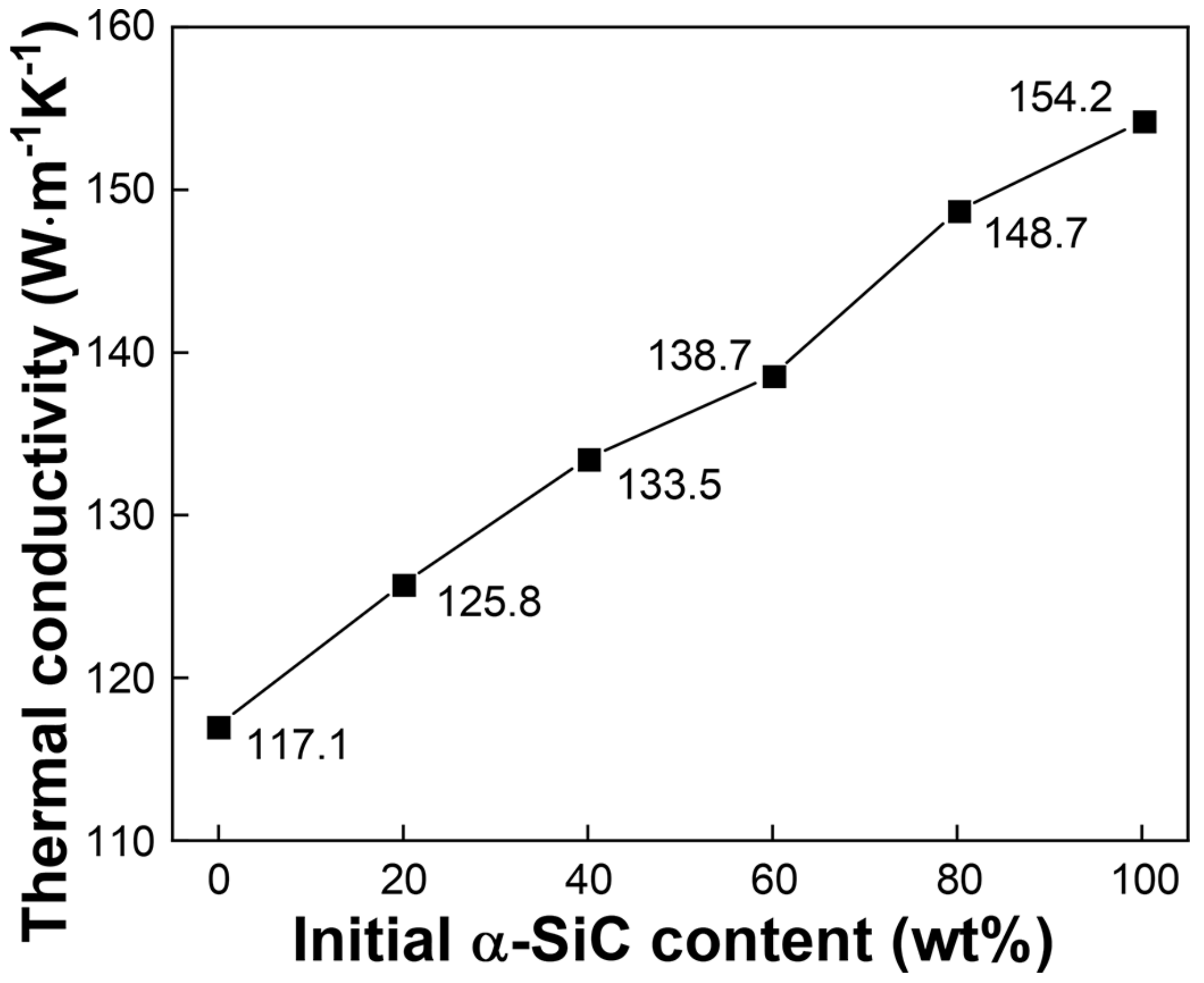

Figure 4

Thermal conductivity of pressureless solid-state sintered SiC ceramics with varying initial a-phase content. 

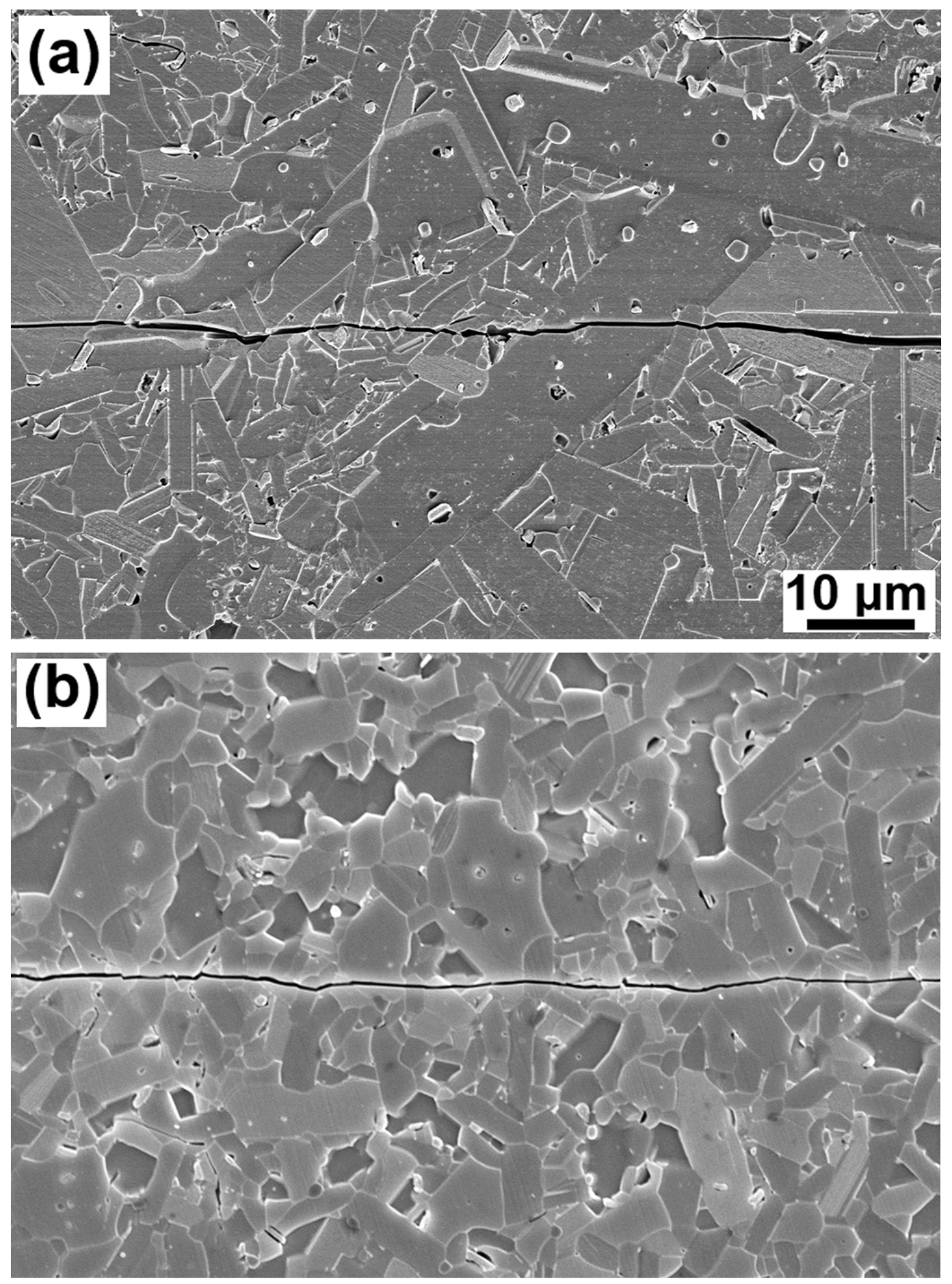

\section{Figure 5}

Crack propagation behavior of pressureless solid-state sintered SiC ceramics: (a) A0 and (b) A100. 

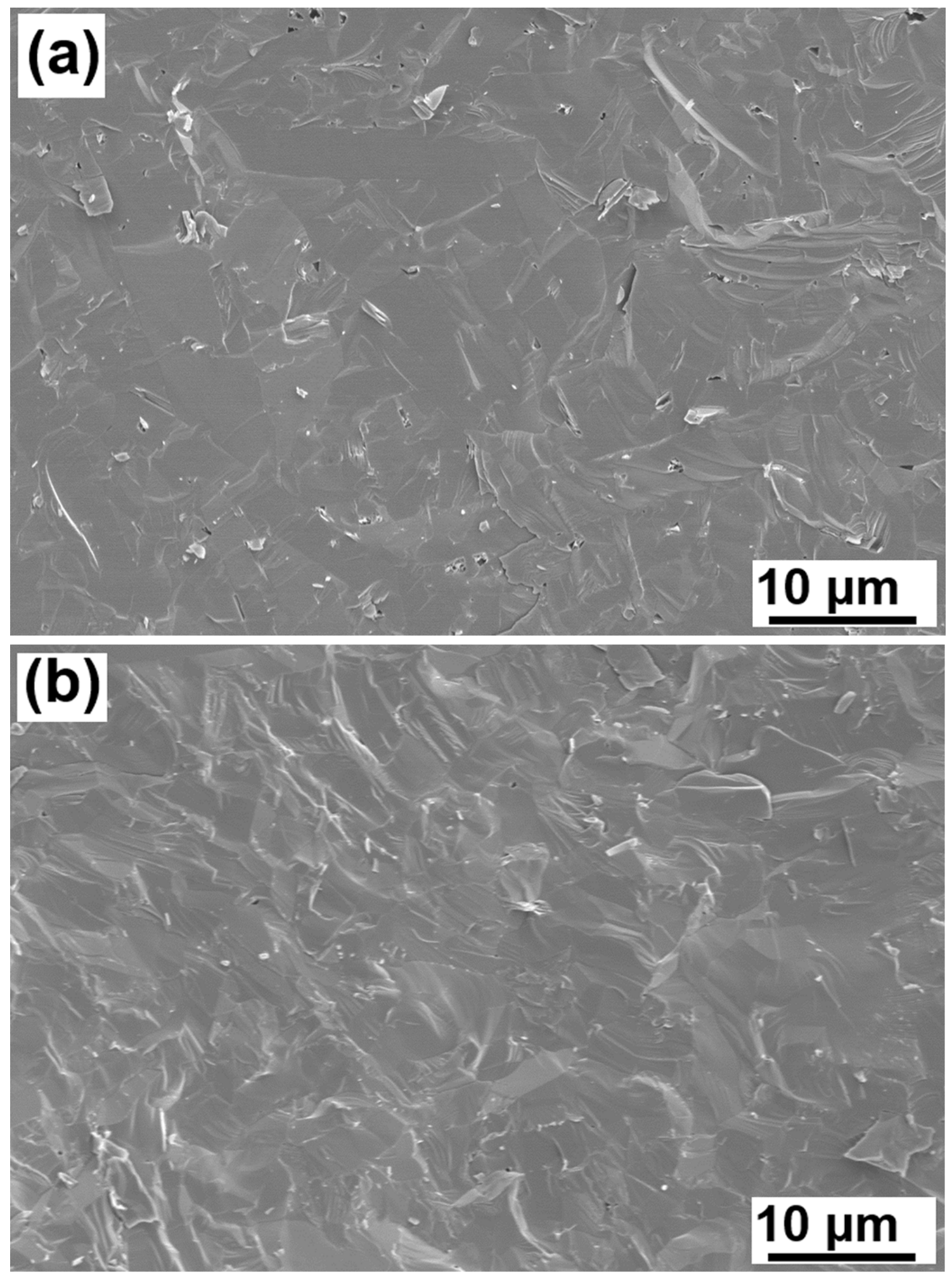

Figure 6

Typical fracture surfaces of pressureless solid-state sintered SiC ceramics: (a) A0 and (b) A100. 


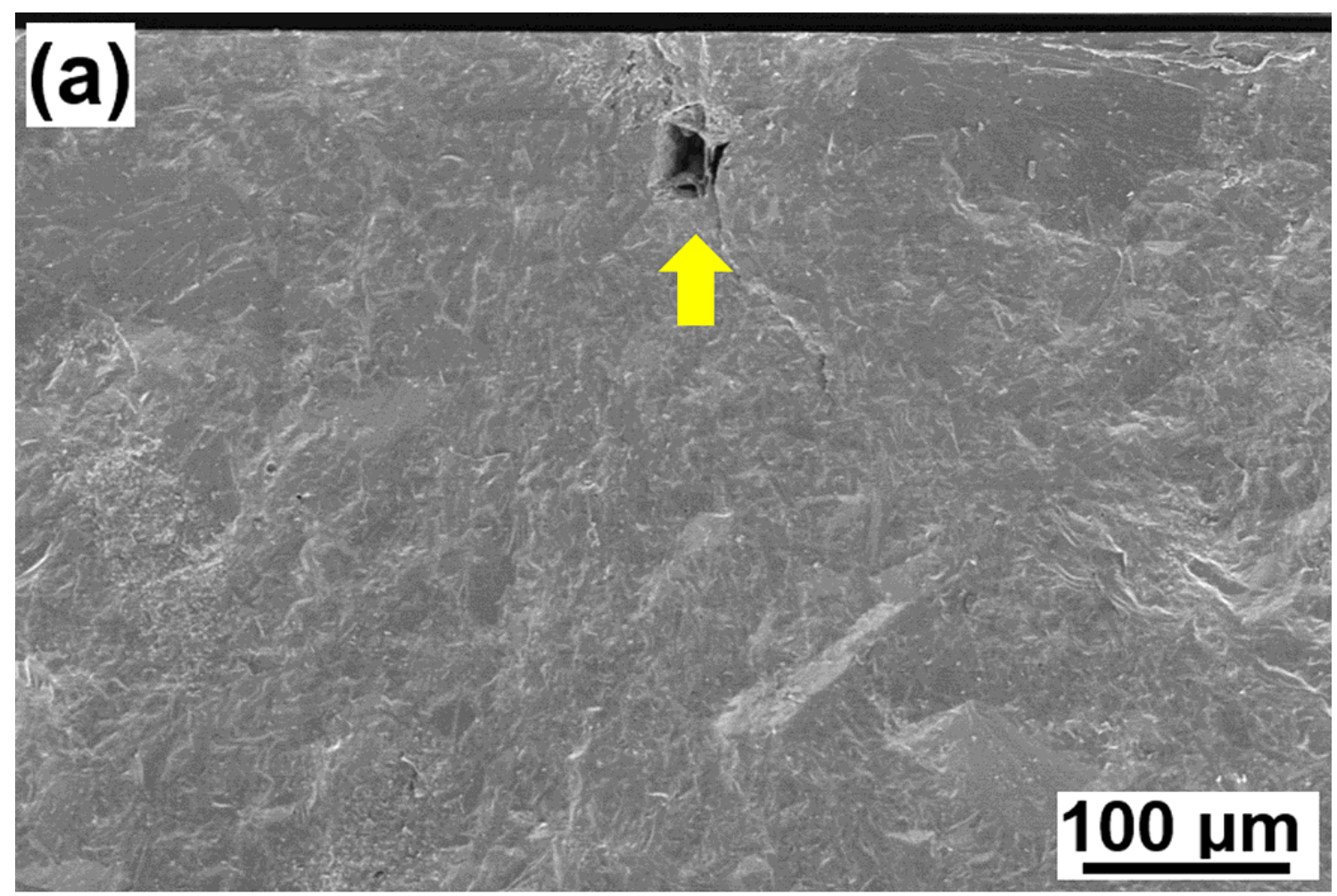

\section{(b)}

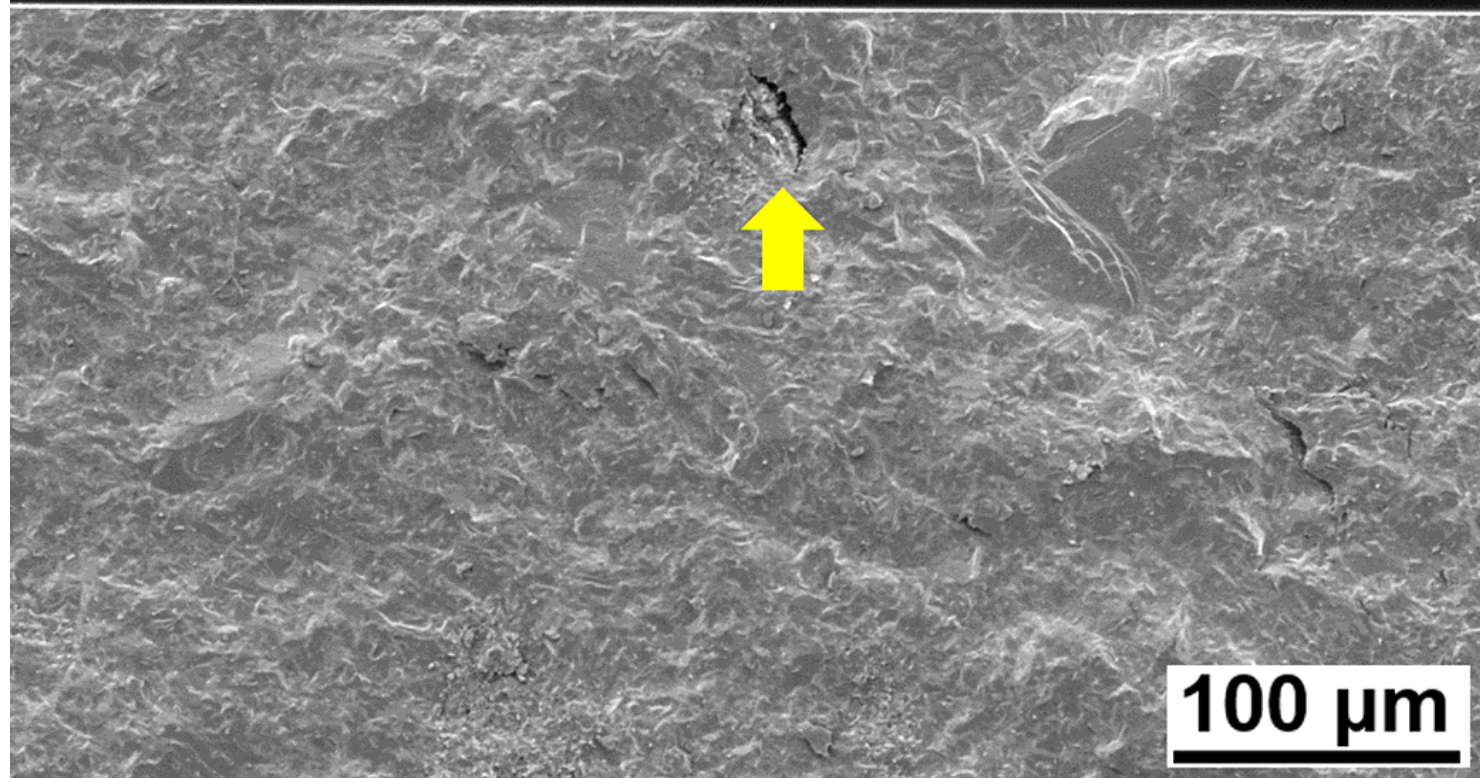

Figure 7

Typical fracture origins of pressureless solid-state sintered SiC ceramics: (a) A0 and (b) A100. 